\title{
Development of an Ultrasonic Process for Soil Remediation
}

by

\author{
J.M. Wu, H.S. Huang, C.D. Livengood
}

\section{Energy Systems Division}

Argonne National Laboratory

Argonne, Illinois 60439

Submitted for publication in

Particulate Science \& Technology

\section{DISCLAIMER}

This report was prepared as an account of work sponsored by an agency of the United States Government. Neither the United States Government nor any agency thereof, nor any of their employees, makes any warranty, express or implied, or assumes any legal liability or responsibility for the accuracy, completeness, or usefulness of any information, apparatus, product, or process disclosed, or represents that its use would not infringe privately owned rights. Reference herein to any specific commercial product, process, or service by trade name, trademark, manufacturer, or otherwise does not necessarily constitute or imply its endorsement, recommendation, or favoring by the United States Government or any agency thereof. The views and opinions of authors expressed herein do not necessarily state or reflect those of the United States Government or any agency thereof.

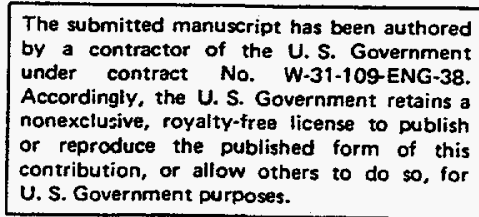

contribution, or allow others to do so, for U. S. Government purposes. 


\section{DISCLAIMER}

Portions of this document may be illegible in electronic image products. Images are produced from the best available original document. 


\title{
Development of an Ultrasonic Process for Soil Remediation
}

\author{
J.M. Wu, H.S. Huang, C.D. Livengood \\ Energy Systems Division \\ Argonne National Laboratory \\ Argonne, Illinois 60439
}

\begin{abstract}
An ultrasonic process for the detoxification of carbon tetrachloride- $\left(\mathrm{CCl}_{4^{-}}\right)$ contaminated soil was investigated in the laboratory by using a batch irradiation reactor equipped with a $600-\mathrm{W}$ ultrasonic power supply operated at a frequency of $20 \mathrm{kHz}$. Key parameters studied included soil characteristics, irradiation time, $\mathrm{CCl}_{4}$ concentration, steady-state operating temperature, applied ultrasonic-wave energy, and the ratio of soil to water in the system. The results of the experiments showed that (1) residual $\mathrm{CCl}_{4}$ concentrations could be decreased with longer irradiation periods and (2) detoxification efficiency was proportional to steady-state operating temperature and applied ultrasonic-wave energy. The characteristics of the contaminated soil were found to be an important factor in the design of an ultrasonic detoxification system. A soil-phase $\mathrm{CCl}_{4}$ concentration below $1 \mathrm{ppm}$ (initial concentration of $56 \mathrm{ppm}$ ) was achieved through this process, indicating that the application of ultrasonic irradiation is feasible and effective in the detoxification of soil contaminated by organic compounds. On the basis of the experimental results, a schematic of a full-scale ultrasonic soil-detoxification system was developed. Improvements to this novel process are discussed.
\end{abstract}




\section{INTRODUCTION}

At a variety of locations throughout the United States, groundwater and soil are contaminated by chlorinated organic compounds. Leaky storage tanks, the improper disposal of spent solvents, and inadequately designed landfills are potential sources of contamination. The most frequently encountered volatile chlorinated organic contaminants, such as carbon tetrachloride $\left(\mathrm{CCl}_{4}\right)$ and trichloroethylene (TCE), are carcinogens and are regulated by the U.S. Environmental Protection Agency (EPA) as Resource Conservation and Recovery Act (RCRA) components. In addition to their pervasiveness in soils, these contaminants are potentially toxic to humans and animals; therefore, options for their treatmeni merit considerable attention.

The detoxification of soils contaminated by volatile organic 'compounds can be achieved via two basic mechanisms: (1) conversion of the contaminants to less toxic compounds (for example, by means of thermal destruction, chemical oxidation, dechlorination, and biodegradation) and (2) physical transfer and concentration of the contaminants to another waste stream for subsequent treatment or recovery (for example, by means of chemical/vapor extraction and low-temperature thermal desorption). The permanent bonding of the contaminants within a stabilized matrix to prevent future leaching (such as immobilization and vitrification) may not be appropriate for these compounds because of their high volatility'(1). Current technologies that have been used to remove toxic organic contaminants from soils include, for example, vapor and solvent extraction, thermal treatment, soil washing, and biodegradation (2-7). Because the 
contaminants are usually strongly sorbed onto the soil matrix, remediation by means of the techniques mentioned above is ineffective and slow, and success has been limited. Alternatives for soil remediation, such as the use of ultraviolet radiation/oxidation, radio frequency heating, and ultrasonic sonication, are under development (8-10). For the treatment of many organic contaminants, the ultrasonic process has the advantages of improving contaminant desorption characteristics and completely destroying or converting the organic compounds, not simply transferring them to another medium.

In this paper, we present the results of a laboratory investigation of the ultrasonic process for the remediation of soils contaminated with volatile organic compounds, such as $\mathrm{CCl}_{4}$. The experiments were performed in a bench-scale batch reactor, and the contaminated soil samples in the reactor were irradiated at a frequency of $20 \mathrm{kHz}$. Some important physical parameters (such as soil characteristics, applied ultrasonic power, operation temperature, and $\mathrm{pH}$ value) that may influence detoxification efficiency and the design of an ultrasonic detoxification system were investigated. Experiments were also conducted to identify the optimal operating condition for the ultrasonic detoxification process. A process diagram of an ultrasonic soil remediation system is presented.

\section{EXPERIMENTAL CONSIDERATIONS}

\section{Reaction Apparatus}

Contaminated soil was irradiated by using an ultrasonic power supply (Sonics \& Materials, VC 600) with a continuously variable output from 0 to $600 \mathrm{~W}$. The system 
was operated at $20 \mathrm{kHz}$. Figure 1 shows a diagram of the experimental apparatus. The ultrasonic power supply transformed line voltage of $50-60 \mathrm{~Hz}$ to high-frequency $(20 \mathrm{kHz})$ electrical energy, which was then transmitted to a piezoelectric transducer within the converter, where it was changed to mechanical vibrations. In the experiments, the probe intensified the mechanical vibrations generated from the converter, thereby creating pressure waves delivered to the medium through a titanium tip. Therefore, the power intensity at the titanium tip could attain $500 \mathrm{~W} / \mathrm{cm}^{2}$, compared with about $1 \mathrm{~W} / \mathrm{cm}^{2}$ for an ultrasonic cleaning bath.

To avoid an unexpected loss of volatile organic contaminants (which would reduce experimental errors), all of the irradiations were conducted in a $50-\mathrm{mL}$ stainless-steel sealed reactor. Cooling water was circulated in a cooling jack outside the processing cell to maintain the operating temperature within the desired range during the experiment.

\section{Materials}

Carbon tetrachloride (certified ACS grade, Mallinckrodt, Inc.) was chosen as the pollutant for the current-stage experiments because it is one of the most frequently detected volatile organic compounds at contaminated sites. Methanol (certified for trace environmental analysis by capillary gas chromatograph and gas chromatograph-mass spectrometry, Bardick \& Jackson) was used as the extractant for the analysis of adsorbed $\mathrm{CCl}_{4}$ in the soil matrix. All of the chemicals were used as-received from the suppliers.

The standard and working $\mathrm{CCl}_{4}$ solutions were prepared by dissolving aliquots of neat (purity greater than $99.9 \%$ ) compound overnight in laboratory organics-free deionized water (the saturated $\mathrm{CCl}_{4}$ concentration was assumed to be $800 \mathrm{mg} / \mathrm{L}$ at $23^{\circ} \mathrm{C}$ ) and 
diluting them with deionized water to the required concentrations. The solutions were stored in capped glass flasks with zero headspace (to minimize volatilization) before use. Standard $\mathrm{CCl}_{4}$ solutions for use in the establishment of analytical calibration curves were prepared by diluting saturated solution in methanol to the desired concentrations. The standard solutions were stored in 5-mL vials with Mininert valves (Supelco, Inc., Bellefonte, PA). Fresh standard solutions were prepared every month to prevent accidental loss or any unexpected change in concentration.

Soil samples for the current-stage experiments were obtained from Sandia National Laboratory (SNL, Livermore site). The samples were known to be contaminated with some petroleum hydrocarbons. Before use, the soil samples were stored at $4^{\circ} \mathrm{C}$ in separate sealed containers in darkness, according to the sampling depth of soils (ranging from $22.5 \mathrm{ft}$ to $95.5 \mathrm{ft}$ ). Table 1 lists some of the chemical and physical characteristics and size distributions of the sample soils used in the experiments. The sample soils were taken from a depth of $56 \mathrm{ft}$, the depth at which the lowest concentrations of petroleum contaminants are found. According to the information provided in Table 1, the selected sample soils were contaminated with $400 \mathrm{mg} / \mathrm{kg}$ of petroleum hydrocarbons; moisture content was $13.6 \%$ (by weight), porosity was $26 \%$, and $\mathrm{pH}$ was 7.7 . Most of the soils were classified as medium-fine sand $(79.81 \%)$ and silty clay (19\%); the rest of the soils were classified as coarse sand (1.19\%). Before the experiments were started, soil samples were dried in an oven at $104^{\circ} \mathrm{C}$ for $24 \mathrm{~h}$ to remove moisture and volatile organic contaminants. When portions of the dried soil samples were extracted by using methanol and analyzed by using gas chromatography, they were found to be $\mathrm{CCl}_{4}$-free. 


\section{Analytical Methods}

The concentrations of aqueous $\mathrm{CCl}_{4}$ were determined by applying a gas chromatograph (GC) unit (Varian 3700) equipped with an electron capture detector. A 10-ft, 1/8-in.-i.d. stainless-steel column packed with an 80/120 Carbopack B/3\%, SP-1500 stabilizer (Supelco, Inc., Bellefonte, PA) was used. A nitrogen gas of greater than 99.999\% purity was applied as carrier gas. A Hewlett-Packard 3380 integrator was connected to the detector and used as the recorder. The $\mathrm{pH}$ value of sample solution was determined by means of a $\mathrm{pH} /$ millivolt meter (Orien Research, Model 611) equipped with a $\mathrm{pH}$ electrode. The $\mathrm{pH}$ meter was calibrated with proper standard solutions before use, and the calibration was confirmed after each experiment. Supplemental experiments (such as the determination of settleable and nonsettleable soils) were conducted by using standard procedures (11).

Soil samples were analyzed for adsorbed $\mathrm{CCl}_{4}$ by equilibrating mixtures of contaminated soil and methanol and by quantifying the $\mathrm{CCl}_{4}$ in the resulting solutions. To extract the $\mathrm{CCl}_{4}$, a known amount of contaminated soil was placed in a capped glass bottle with a known amount of methanol extractant, the bottle was shaken roughly by hand and equilibrated for $1 \mathrm{~h}$ on a stirrer, and then the bottle was centrifuged. The amount of $\mathrm{CCl}_{4}$ was measured by direct GC column injection of an aliquot of the resultant supernatant; the procedure was then repeated. The second methanol extraction did not yield any significant additional $\mathrm{CCl}_{4}$, indicating that one methanol extraction was sufficient for the determination of the total $\mathrm{CCl}_{4}$ in the soil. The average efficiency of $\mathrm{CCl}_{4}$ recovery as a result of the use of the procedure described above was about $92 \%$, 
which is considered acceptable for the subsequent experiments.

For the routine determination of $\mathrm{CCl}_{4}$-contaminated soil samples, the soil was mixed with methanol extract at a 1:5 ratio (on a weight basis), shaken roughly by hand for $1 \mathrm{~min}$, equilibrated on a stirrer overnight $(12 \mathrm{~h}$ ), and then centrifuged. To determine the total $\mathrm{CCl}_{4}$ in the soil sample, the $\mathrm{CCl}_{4}$ was quantified by the direct $\mathrm{GC}$ column injection of $1 \mu \mathrm{L}$ of the resultant supernatant. The $\mathrm{CCl}_{4}$ concentration was multiplied by the sum of the volume of methanol used and that of the water previously in the soil.

\section{Experimental Procedures}

Ultrasonic detoxification of soil contaminated by organic compounds involves desorption and destruction stages. The mechanism underlying the process can be understood by determining the reversibility of freshly adsorbed compound $\left(\mathrm{CCl}_{4}\right)$ onto the soil matrix. In the adsorption studies, known amounts of soil samples were placed in $25 \mathrm{~mL}$ glass vials, which were completely filled (to minimize headspace) with known concentrations of $\mathrm{CCl}_{4}$ and capped with $\mathrm{Teflon}^{\mathrm{TM}}$-faced silicone septa. All of the experiments were performed at a room temperature of $20^{\circ} \mathrm{C}$, and the samples were agitated continuously for $72 \mathrm{~h}$ with a motor-driven reciprocating shaker (Eberbach 6010, Eberbach Co., Ann Arbor, MI). At the end of the agitation period, the vials were centrifuged at 2,350 rpm for $30 \mathrm{~min}$ (centrifuge model CU-5000, International Equipment Co., Needham Heights, MA), and $1 \mu \mathrm{L}$ of the supernatant from each sample was directly injected into the $\mathrm{GC}$ for the analysis of residual $\mathrm{CCl}_{4}$ concentrations. The results were converted to the adsorption capacity of the soils (in $\mathrm{mg} \mathrm{CCl} / \mathrm{kg}$ soil).

To verify the results obtained by using the above method, methanol extraction was 
performed so that the adsorption capacity could be directly obtained from the soil phase. In the experiment, a certain amount of completely mixed solution was withdrawn and extracted with methanol for the adsorbed $\mathrm{CCl}_{4}$. The resultant supernatant was analyzed, and the amount of detected $\mathrm{CCl}_{4}$ was subtracted from the amount of $\mathrm{CCl}_{4}$ already in the solution. This quantity was then compared with the quantity of $\mathrm{CCl}_{4}$ obtained from the liquid phase.

For the detoxification experiments, duplicate but larger amounts of soil/water/contaminant samples were prepared by using the sample preparation procedure described above in the adsorption studies. A 50-mL sample of the completely mixed contaminated soil (with corresponding $\mathrm{CCl}_{4}$ equilibrium concentrations in the solution) was then placed in a stainless-steel retactor and sonicated for a given period. Cooling water was circulated through the reactor to maintain constant operating temperatures. Throughout the experiment, all of the sonications were performed in a closed system. At each sampling interval, a certain amount of sample was withdrawn, and the residual concentration of $\mathrm{CCl}_{4}$ was analyzed.

\section{RESULTS AND DISCUSSION}

The detoxification of $\mathrm{CCl}_{4}$-contaminated soil was achieved by exposing the contaminated soil/water mixture to ultrasound and sonicating the mixture for a given period. In general, when ultrasonic-wave energy is introduced and transmitted through the aqueous solution, numerous rarefaction/compression cycles are generated, thereby 
creating millions of microscopic bubbles (cavities). The microbubbles gradually grow along with the rarefaction/compression cycles and finally collapse, leading to the release of a large amount of energy to the system. This phenomenon, referred to as cavitation, would produce a powerful shearing action in the system and cause adsorbed organic molecules on the soil surface to become intensely agitated and eventually desorbed from the soil matrix. In addition, the repeated rarefaction/compression cycles could also enhance diffusion velocities of molecules in the system and thus increase desorption rates. In an aqueous system irradiated with ultrasonics, the desorbed organic compounds may be directly decomposed or oxidized because of local super hot spots and radicals generated during the cavitation processes. Consequently, under an ultrasonic field, the adsorbed organic compounds in the soil matrix can be desorbed, destructed, and finally removed from the system.

\section{Determination of Adsorption Isotherm}

In the batch equilibrium studies, eight sets of duplicate samples, each containing $8 \mathrm{~g}$ of $\mathrm{CCl}_{4}$-free soil, were equilibrated for $72 \mathrm{~h}$ with aqueous $\mathrm{CCl}_{4}$ solutions at concentrations ranging from 40 to $120 \mathrm{mg} / \mathrm{L}$. The amount of $\mathrm{CCl}_{4}$ adsorbed onto the soil was calculated on the basis of the difference between the aqueous $\mathrm{CCl}_{4}$ concentrations at the beginning and at the end of the equilibration period. The experimental results are shown in Figure 2. An extended equilibrium period of one week did not yield any significant difference in adsorption capacity; therefore, equilibrium is assumed to be reached within $72 \mathrm{~h}$. The adsorption capacity was found to be directly proportional to the aqueous $\mathrm{CCl}_{4}$ equilibrium concentration (the higher the aqueous equilibrium concentration, 
the higher the soil $\mathrm{CCl}_{4}$ concentration). A linear relationship was observed, and Henry's law holds within the current concentration range. A partition coefficient was determined to be 1.28 on the basis of the linear model, $\mathrm{q}_{e}=\mathrm{K}_{\mathrm{p}} \mathrm{C}_{\mathrm{e}}$, where $\mathrm{K}_{\mathrm{p}}$ is the partition coefficient $(\mathrm{L} / \mathrm{kg}), \mathrm{C}_{e}$ is the solution-phase $\mathrm{CCl}_{4}$ concentration $(\mathrm{mg} / \mathrm{L})$, and $\mathrm{q}_{e}$ is the solidphase $\mathrm{CCl}_{4}$ concentration $(\mathrm{mg} / \mathrm{kg})$.

After the adsorption equilibrium was reached and the sample was analyzed, the sample was centrifuged again and clean supernatant was removed. The soil was then extracted with methanol to study the recovery efficiency of $\mathrm{CCl}_{4}$ adsorbed onto the soil matrix. Also, through methanol extraction, the adsorption capacity could be determined directly from the soil phase. The result was found to be close to the adsorption capacity obtained from the liquid phase, and the average recovery ratio was found to be about $92 \%$ (85\%-99\%) through this process.

\section{Determination of Detoxification Efficiency}

The experiments for the detoxification (desorption and destruction of $\mathrm{CCl}_{4}$ ) of the $\mathrm{CCl}_{4}$-contaminated soil was investigated by using a batch-processing unit. In the experiments, the contaminated soil samples with corresponding equilibrium $\mathrm{CCl}_{4}$ concentrations, were placed in a 50-mL stainless-steel processing cell and sonicated for a given period. The results are shown in Figure 3. Since $\mathrm{CCl}_{4}$ is such a highly volatile organic compound, the complete separation of $\mathrm{CCl}_{4}$-contaminated soil and equilibrium solution, without the generation of some experimental errors during the processes, was extremely difficult. Therefore, to minimize experimental error, the desired amount of soil/water mixture for ultrasonic irradiation that contained the corresponding equilibrium 
concentrations of contaminant $\left(\mathrm{CCl}_{4}\right)$ in the aqueous phase was directly transferred from the adsorption bottle to the processing cell without further treatment (such as the separation of sample soil and equilibrium solution). The results were expressed in terms of total amount of $\mathrm{CCl}_{4}$ in transferred volume (including the $\mathrm{CCl}_{4}$ in soil matrix and the $\mathrm{CCl}_{4}$ in the aqueous phase) in units of $\mathrm{mg} / \mathrm{L}$ ( $\mathrm{mg}$ of residual $\mathrm{CCl}_{4}$ concentration/liter of mixture). Figure 3 shows that the initial amount of $\mathrm{CCl}_{4}(60 \mathrm{mg} / \mathrm{L})$ decreased gradually under the ultrasonic field, down to about $17.5 \mathrm{mg} / \mathrm{L}$ within $6 \mathrm{~min}$ of sonication. Another experiment with an initial $\mathrm{CCl}_{4}$ volume of $55 \mathrm{mg} / \mathrm{L}$ showed a similar decreasing profile. In other experiments, an extended sonication period of $25 \mathrm{~min}$ for this solution resulted in a significant decrease of $\mathrm{CCl}_{4}$ to $0.5 \mathrm{mg} / \mathrm{L}$, which corresponds to a soil-phase $\mathrm{CCl}_{4}$ concentration below $1 \mathrm{ppm}$ by weight, if all of the detected contribution were from the soil phase. These results clearly indicate that ultrasonic decontamination is a feasible technology for the remediation of $\mathrm{CCl}_{4}$-contaminated soil.

\section{Effect of Soil Characteristics}

All of the results mentioned and discussed in this paper are presented on the basis of dry soil weight and could be converted to actual soil weight by multiplying the dry soil weight by the moisture content of the soil. The effects of soil moisture on the sorption of organic compounds onto soils have been extensively studied by many researchers (12-14) and therefore are not discussed here. An average value of $13.6 \%$ moisture content for the selected sample soils was experimentally determined in the laboratory, indicating that water molecules contribute about one-eighth of the total soil weight. In addition to soil moisture, other major properties of the soil used in the study are presented 
in Table 1.

Another significant parameter in the determination of detoxification processes and the size of detoxification units is the portions of settleable matter in the sample soils. As shown in Table 1, the sample soils are classified into two major parts: sand (large particles) and clay (small particles). On the basis of our experimental results, most of the organic compounds adsorbed onto the soil are concentrated on the surface of clay-type soils, which have (1) very large surface areas relative to their volumes and (2) surface properties that encourage organic adsorption. Furthermore, most of the clay particles are too small to settle in water and, hence, may need to be remediated. On the other hand, only a small amount of the organic compound is adsorbed onto the nonsettleable soil or even onto larger particles of the soil. In this case, the organic compound could be directly removed through precipitation and may not need further treatment.

The portions of settleable soil at room temperature in water were determined by following standard methods (11), as mentioned in the experimental section; the average result from this analysis was $95.7 \pm 0.3 \%$ (by weight). In other words, the amount of nonsettleable soil was only about $4.7 \%$ of the total weight, suggesting that probably less than $5 \%$ of the total contaminated soil needs ultrasonic remediation. The loading of soils to the ultrasonic detoxification unit may also be reduced by this ratio.

After all of the supernatant was removed, the settleable soil was washed with water three times (with the total amount of washing water equal to ten times the weight of the soil), and then the soils were extracted by using methanol and analyzed for remaining $\mathrm{CCl}_{4}$. No significant amount of $\mathrm{CCl}_{4}$ was detected (the $\mathrm{CCl}_{4}$ concentration in 
this case was lower than $1 \mathrm{mg} / \mathrm{kg}$ ) in the soil matrix, indicating that the settleable sand particles can be remediated simply by washing the soil with water. Since the solubility of $\mathrm{CCl}_{4}$ in water is relatively low, it is believed that the surface properties of settleable soils do not encourage adsorption. The $\mathrm{CCl}_{4}$, in this case, is simply attached (or coated) onto the surface of the soils and, hence, can easily be washed out. The $\mathrm{CCl}_{4}$ concentrations on the surface of the settleable sand and suspended clay have not been determined in the laboratory. However, it is estimated that greater than $80 \%$ of the adsorbed $\mathrm{CCl}_{4}$ would go to the supernatant, while less than $20 \%$ of the $\mathrm{CCl}_{4}$ would remain in the settleable sand. Therefore, approximately one-fifth of the adsorbed $\mathrm{CCl}_{4}$ could be removed by washing the soil. The washed water, which probably contains high concentrations of $\mathrm{CCl}_{4}$, would then be ultrasonically remediated and recycled.

\section{Effect of Applied Ultrasonic Power}

One of the most important parameters on the detoxification of organicscontaminated soil is probably the applied ultrasonic power. Increasing the applied ultrasonic power would simultaneously increase the shearing force on the surface of soil matrix and the diffusion velocities of organic compounds in irradiated solution; together, these phenomena would enhance the desorption efficiency of adsorbed compounds from soils. Furthermore, increasing the applied ultrasonic power could also increase the destruction efficiency of desorbed organic compounds in aqueous solution (15). As a resuit, at a higher level of applied ultrasonic power, the adsorbed organic compounds would be much easier to be desorbed and then decomposed, thereby improving the detoxification efficiency of the system. 
Figure 4 presents the experimental results obtained in the investigation of soil detoxification rate as it was affected by applied ultrasonic power. The applied ultrasonic power was adjusted and controlled through a controller located on the front panel of the power supply and expressed as a percent of the available maximum output power. Within the current range of experimental input power, it was found that the $\mathrm{CCl}_{4}$ detoxification rate was about directly proportional to the applied ultrasonic power. An initial total concentration of $\mathrm{CCl}_{4}$ of $57 \mathrm{mg} / \mathrm{L}$ decreased to $22 \mathrm{mg} / \mathrm{L}$ within $5 \mathrm{~min}$ of irradiation, and more $\mathrm{CCl}_{4}$ was destructed in the same irradiation period as ultrasonic power was increased. A linear relationship was observed between detoxification rate and applied ultrasonic power. At a very high input power (beyond the current experimental range), the detoxification rate might not follow the above relationship because of the decreasing destruction efficiency of organic compounds in aqueous solution.

\section{Effect of Operating Temperature}

Wu et al. have shown that the operating temperature would not affect the ultrasonic destruction efficiency of $\mathrm{CCl}_{4}$ in aqueous solution (16). However, in the investigation of the ultrasonic detoxification of $\mathrm{CCl}_{4}$-contaminated soil, it was found that operating temperature did slightly affect the detoxification rate within the temperature range of the experiment $\left(15-60^{\circ} \mathrm{C}\right)$. The relationship between operating temperatures and final $\mathrm{CCl}_{4}$ concentration of a soil/water mixture after $2 \mathrm{~min}$ of sonication is shown in

Figure 5. The results indicate that the higher the operating temperature, the lower the residual $\mathrm{CCl}_{4}$ concentration, thus suggesting that increasing the operating temperature could increase the detoxification rate of a soil/water mixture in an ultrasonic field. The 
detoxification rate would be increased because increasing the operating temperature could increase the internal energy of adsarbed molecules, provide the required desorption energy, and make the adsorbed molecules more easily desorbed. In addition, a higher operating temperature could increase the diffusion velocities of desorbed molecules and thus increase the desorption rate. Therefore, on the basis of the above information, the detoxification of $\mathrm{CCl}_{4}$-contaminated soil can be made more efficient by operating the system at a higher temperature (up to $60^{\circ} \mathrm{C}$ ).

\section{Effect of Suspended Soil Concentration}

Another important parameter in the design of an ultrasonic detoxification system is the dilution factor (expressed as $g$ dilution water/g soil) of an irradiated soil/water mixture. If the soil/water dilution factor is low, then the suspended soil concentration is high; thus, the total concentrations of target organic compounds are higher and the total volume of soil/water mixture to be remediated is lower. As shown in Figure 6, which presents the experimental results obtained for corresponding samples at identical power input but different dilution factors, sample slurries with lower dilution factors required longer irradiation times to reach comparable detoxification levels. To determine the total irradiation time required to detoxify a given volume of contaminated soil to a designated concentration level, the irradiation time, as obtained in Figure 7, must be multiplied by a corresponding dilution factor. That is,

Total required irradiation time $=$ (Irradiation time obtained in experiment at a specific dilution factor) $\mathrm{x}$ (dilution factor).

On the basis of the information obtained in Figure 6, total required irradiation 
times were calculated for sample mixtures with different dilution factors at various treatment levels; the calculated results versus various dilution factors are shown in Figure 7. As can be seen in the figure, the optimum dilution factor that resulted in the shortest required irradiation time at identical power input depends on the desired treatment level. For a $\mathrm{CCl}_{4}$ treatment level of below $3 \mathrm{mg} / \mathrm{L}$, the optimum dilution factor is about 3.9 , but the value increases to about 6.4 when the desired $\mathrm{CCl}_{4}$ treatment level is increased to 5 $\mathrm{mg} / \mathrm{L}$. The optimum dilution factor changes as a function of the characteristics of the designated organic contaminants and, especially, the characteristics of irradiated soil samples. Therefore, to specify the optimum dilution factor at a selected treatment level, treatability experiments need to be carried out to obtain information about the relationship between irradiation time and dilution factor before the actual ultrasonic remediation work is conducted.

\section{Optimum Operating Condition}

The input ultrasonic power and dilution factor concurrently determine the total time and cost of treatment. In general, an increase in the input ultrasonic power (up to a certain level) and a decrease in the water/soil dilution factor would increase the detoxification rate. However, it was observed from experiments that at a relatively high ultrasonic power level and low dilution factor (high suspended soil concentration), sample soils could be crushed by the input ultrasonic energy and subsequently turned into very fine particles, changing the characteristics of irtadiated mixture into a silty slurry with very high viscosity. In the experiment, the mixing capability of the irradiated mixture decreased, and eventually, the mixing capability of the water/soil mixture was terminated 
and detoxification efficiency was hampered. Increasing the dilution factor of the irradiated mixture and/or reducing the applied ultrasonic power may avoid the occurrence of this phenomenon, but these changes could increase the volume of the slurry and hence increase total irradiation time and final remediation cost. Therefore, the optimum operating condition for the ultrasonic detoxification process should be experimentally determined for individual soil types.

\section{Process Development}

On the basis of the information presented above, a process flow diagram for the ultrasonic detoxification system has been developed (see Figure 8). As shown in the figure, the contaminated soil is first sieved to remove large stones and foreign objects and then completely mixed with water. The soil/water mixture is allowed to flow through a sedimentation tank to separate settleable sand particles and nonsettleable clay particles, and then the supernatant (clay particles) is directed to the ultrasonic detoxification units for sonication. The settleable sand particles are removed from the bottom of the sedimentation tank and washed with $\mathrm{CCl}_{4}$-free water. The washed water is also directed to the ultrasonic processing units for treatment. The washed sand particles may not require any further treatment and may be discharged. The remediated soil, after dewatering, could be backfilled to the excavation site. Finally, the used water (with a pH value around 3) could be discharged and/or recycled after neutralization. 


\section{CONCLUSIONS}

The initial adsorption and detoxification experiments in bench-scale systems indicated that ultrasonic detoxification is a feasible technology for the effective removal organic compounds (such as $\mathrm{CCl}_{4}$ ) from the soil matrix. The adsorption capacity of the SNL sample soil is directly proportional to the liquid-phase $\mathrm{CCl}_{4}$ equilibrium concentrations within the current experimental concentration range. A linear relationship between the soil- and liquid-phase $\mathrm{CCl}_{4}$ concentrations (with a partition coefficient of 1.28 on the linear model) was obtained. Kinetic studies revealed that $\mathrm{CCl}_{4}$-contaminated soil can be successfully detoxified by means of ultrasonic irradiation. Greater than $99 \%$ of the $\mathrm{CCl}_{4}$ was destroyed within 25 min of sonication. In addition, the soil detoxification rate was found to be directly proportional to both the applied ultrasonic power and the operating temperature within the current experimental power and temperature ranges. Increasing the input power and raising the operating temperature enhance the degree to which organics-contaminated soils are detoxified. In the determination of the optimal operating condition, the dilution factor of the soil/water mixture and the applied ultrasonic power were found to be the principal parameters. In a soil-detoxification system, the optimal operating conditions for individual sample soils should be obtained through treatability experiments, whereby either the ultrasonic input power or the dilution factor is adjusted in the system and all of the other physical conditions are identical.

In the development of an ultrasonic soil-detoxification process, preliminary studies with the SNL soil samples revealed that about $95 \%$ of the investigated soil sample was 
settleable and could be removed through precipitation. The settleable portions of soil could be easily remediated by washing the soil with washed water recycled for reuse or for remediation. The remaining $5 \%$ supernatant could be directly introduced into the ultrasonic detoxification unit to be remediated, and the remediated soil may be backfilled to the excavation site.

\section{ACKNOWLEDGMENT}

This work was supported by the U.S. Department of Energy, Assistant Secretary for the Environmental Restoration and Waste Management, Office of the Technology Development, under contract W-31-109-Eng-38. 


\section{References:}

1. Kostecki, P.T.; Calabrase, E.J.; Bonazountas, M. Hydrocarbon Contaminated Soils. Lewis Publishers, Chelsea, MI, 1992.

2. Travis, C.C.; Macinnis, J.M. Vapor Extraction of Organics from Subsurface Soils. Environ. Sci. Technol. 1985, 26, 1885-1887.

3. Erickson, D.C.; White, E.; Loehr, R.C. Comparison of Extraction Fluids Used with Contaminated Soils. Hazardous Waste \& Hazardous Materials 1991, 8, 185194.

4. Abdul, A.S.; Gibson, T.L.; Rai, D.N. Selection of Surfactants for the Removal of Petroleum Products from Shallow Sandy Aquifers. Ground Water 1990, 28, 920-926.

5. Troxler, W.; Cudahy, J.; Yezzi, J.; Zink, R.; Rosenthal, S. Thermal Desorption: Now You're Cookin'. Soils 1992, June-July, 30-47.

6. Aines, D.A.; Newmark, R.L. Rapid Removal of Underground Hydrocarbon Spills. Energy \& Technology 1992, July, 1-7.

7. Muraka, I.P. Degradation of Organic Compounds in Contaminated Soils. EPRI Journal 1993. March 34-38.

8. U.S. Environmental Protection Agency. Synopses of Federal Demonstrations of Innovative Site Remediation Technologies. EPA/540/8-91/009.

9. Kasevich R.; Holmes, R; Faust, D.; Belesski, R. Radio Frequency Heat Enhances Contaminant Removal. Soils 1993, March, 18-23. 
10. Wekhof, A. Treatment of Contaminated Water, Air and Soil with UV Flashlamps. Environmental Progress 1991, 10, 241-247.

11. Standard Method for the Examination of Water and Wastewater. 14th edition. APHA-AWWA-WPCF 1975.

12. Noll, K.E.; Gounaris, V.; Hou, W. Adsorption Technology for Air and Water Pollution Control. Lewis Publishers, Chelsea, MI, 1992.

13. Smith J.A.; Chiou, C.T.; Kammer, J.A.; Kile, D.E. Effect of Soil Moisture on the Sorption of Trichloroethene Vapor to Vadose-Zone Soil at Picatinny Arsenal, New Jersey. Environ. Sci. Technol. 1990. 24, 676-682.

14. Pennell, K.D.; Rhue, R.D.; Rao, S.C.; Johnston, C.T. Vapor-Phase Sorption of P-Xylene and Water on Soils and Clay Minerals. Environ. Sci. Technol. 1992. $26,756-762$.

15. Wu, J.M.; Huang, H.S.; Livengood C.D. Ultrasonic Destruction of Chlorinated Compounds in Aqueous Solution. Environmental Progress 1992. 11, 195-201.

16. Wu, J.M.; Huang, H.S.; Livengood C.D. Development of an Ultrasonic Process for Detoxifying Groundwater and Soil: Laboratory Research. Annual Report 1991. ANL/ESD/TM-32. 


\section{Table \& Figure Captions:}

Figure 1. Experimental Apparatus

Table 1 Characteristics and Size Distribution of the Selected Soil Samples

Figure 2. Adsorption Isotherm of SNL Sample Soils

Figure 3. Residual $\mathrm{CCl}_{4}$ Concentration versus Sonication Time

Figure 4. Residual $\mathrm{CCl}_{4}$ Concentration versus Applied Ultrasonic Power

Figure 5. Residual $\mathrm{CCl}_{4}$ Concentration versus Steady-State Operating Temperature

Figure 6. Effect of Suspended Soil Concentration

Figure 7. Total Required Sonication Time versus Dilution Factor

Figure 8. Ultrasonic Process for Detoxification of Contaminated Soil 


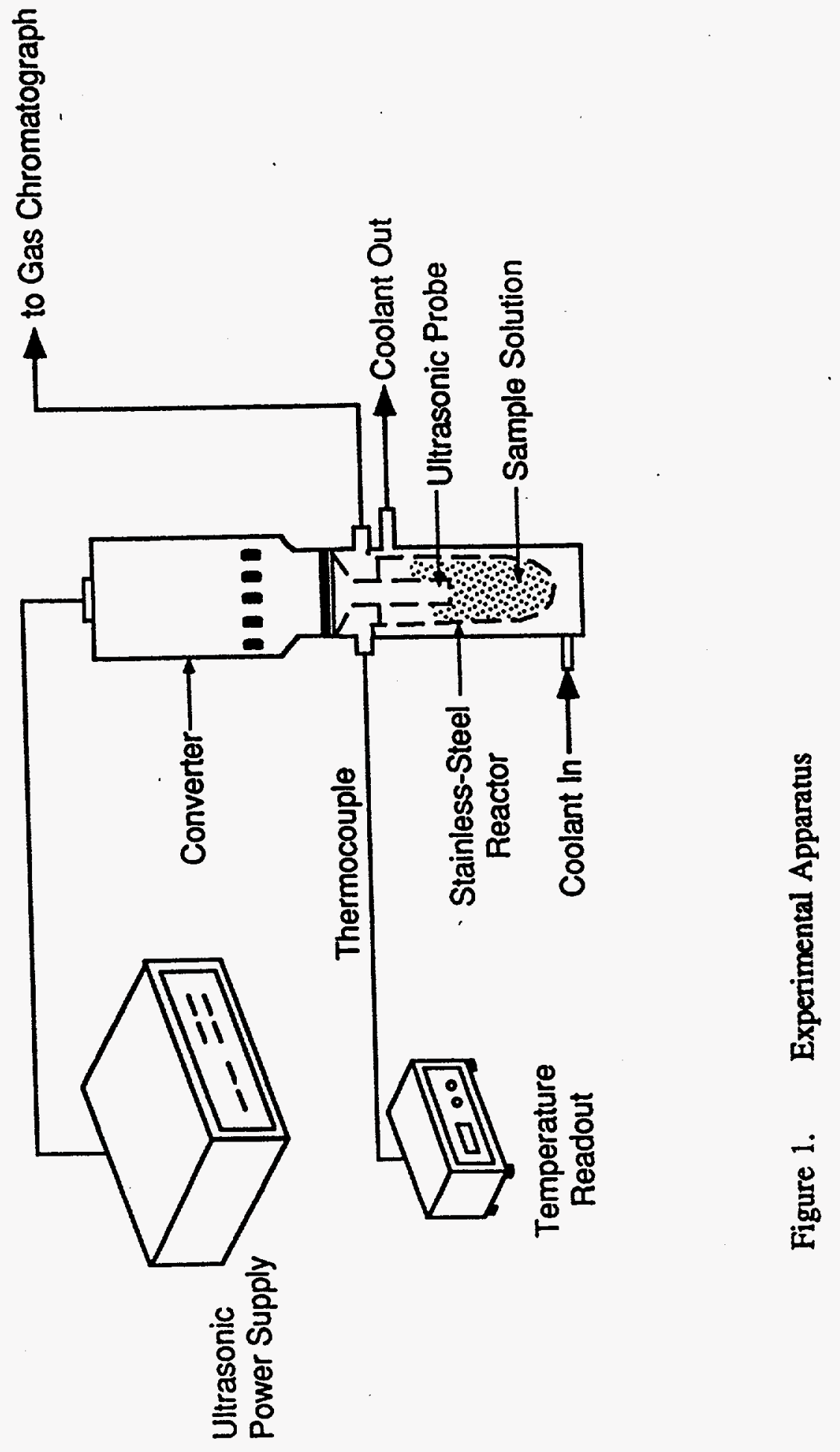


Table 1 Characteristics and Size Distribution of the Selected Soil Samples

Parameter

Characteristic Value

Soil Characteristics

Total petroleum hydrocarbons $(\mathrm{mg} / \mathrm{kg})$

Dry soil (\%)

Moisture content (\%)

Porosity (\%)

Silk and clay content

Medium-Fine sand (\%)

Coarse sand (\%)

$\mathrm{pH}^{2}$
400
86.4
13.6
26.0
19
79.81
1.19
7.7

Size Distribution

\begin{tabular}{llllll}
\hline \multicolumn{6}{c}{ Sieve Size } \\
\hline 4 & 10 & 20 & 60 & 140 & 200 \\
\hline 1.2 & 7.6 & 28.7 & 56.7 & 70.3 & 74.5
\end{tabular}

$\%$ greater than sieve size

- As determined according to EPA Method 9045 


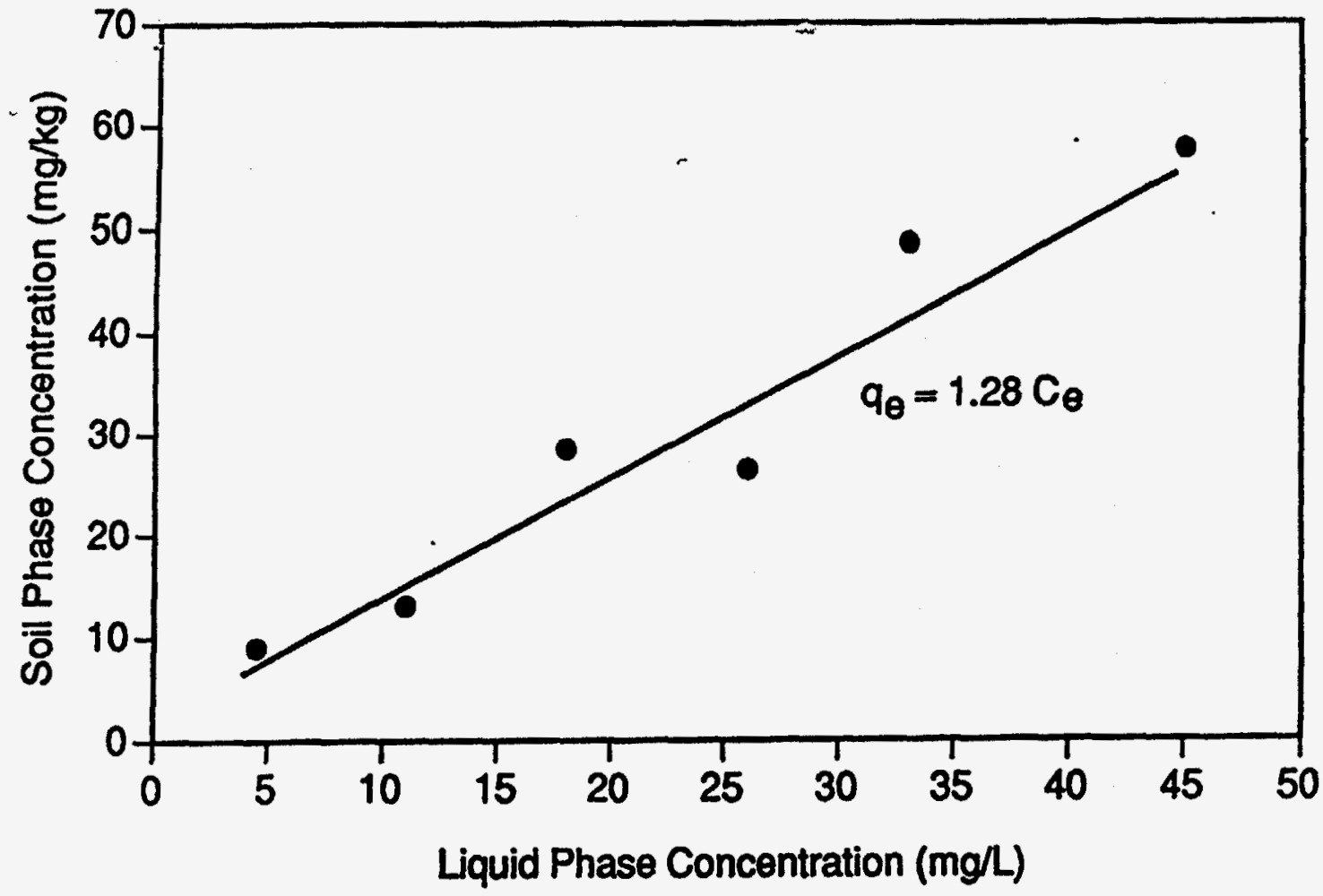

Figure 2. Adsorption Isotherm of SNL Sample Soils 


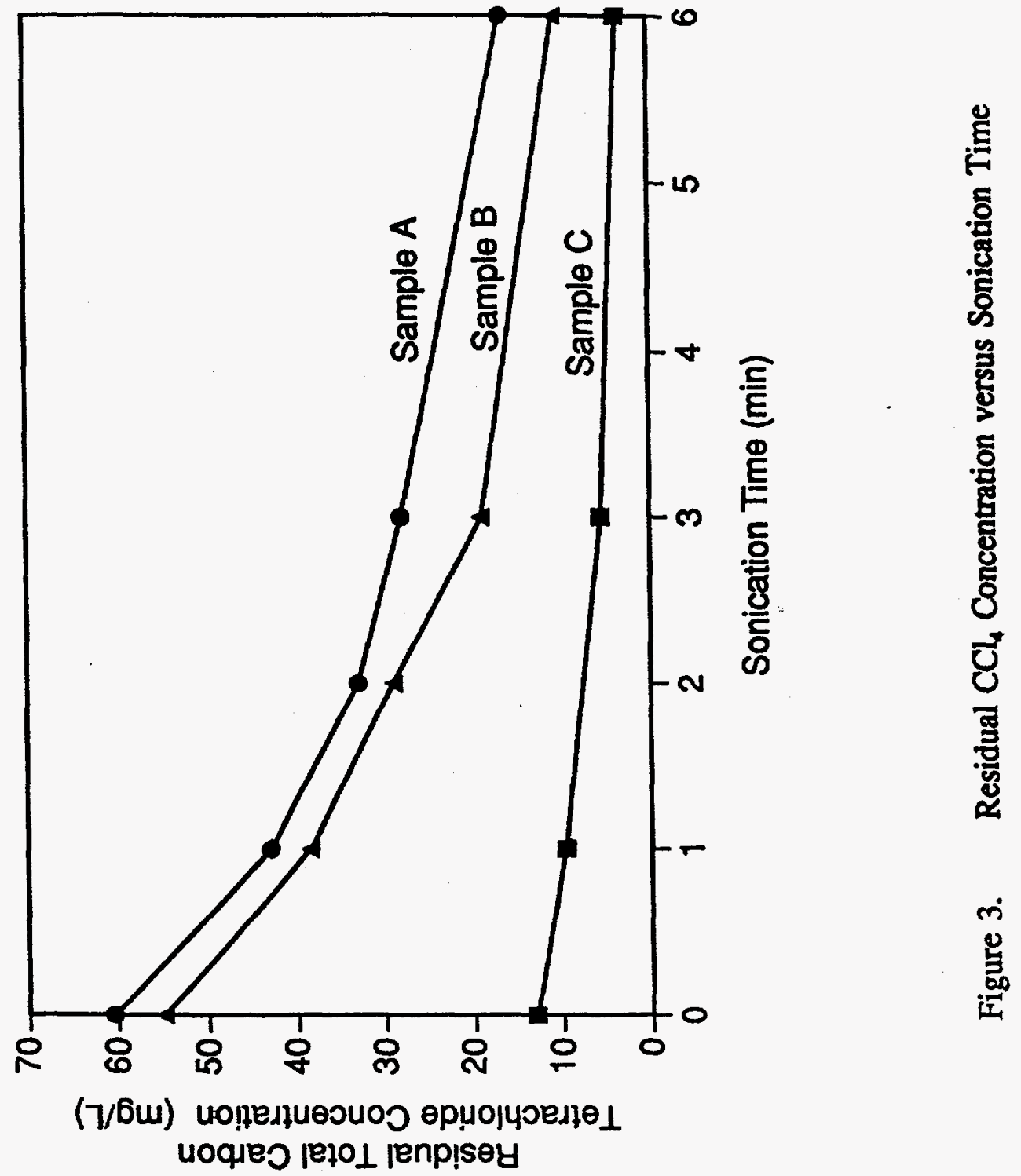




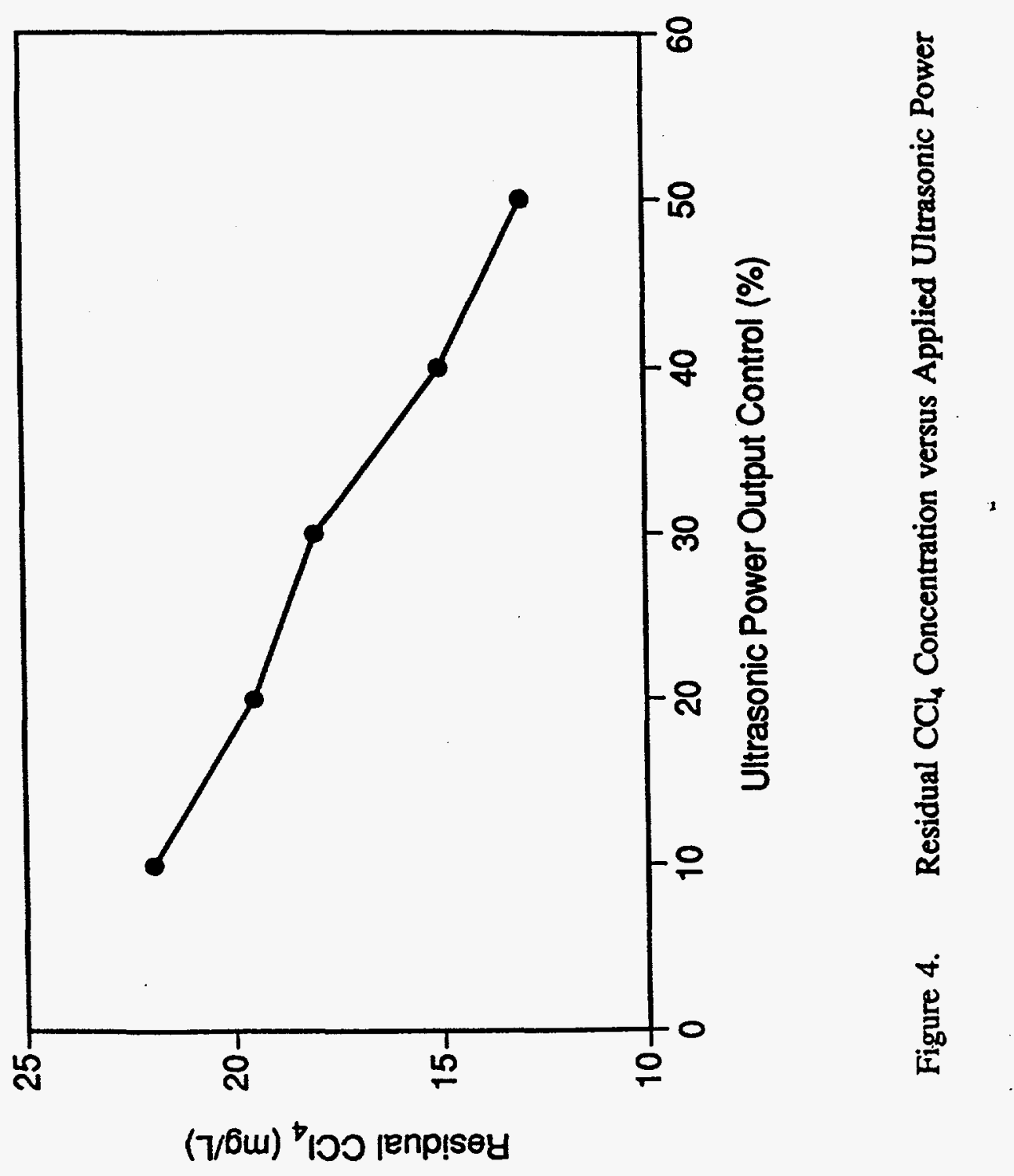




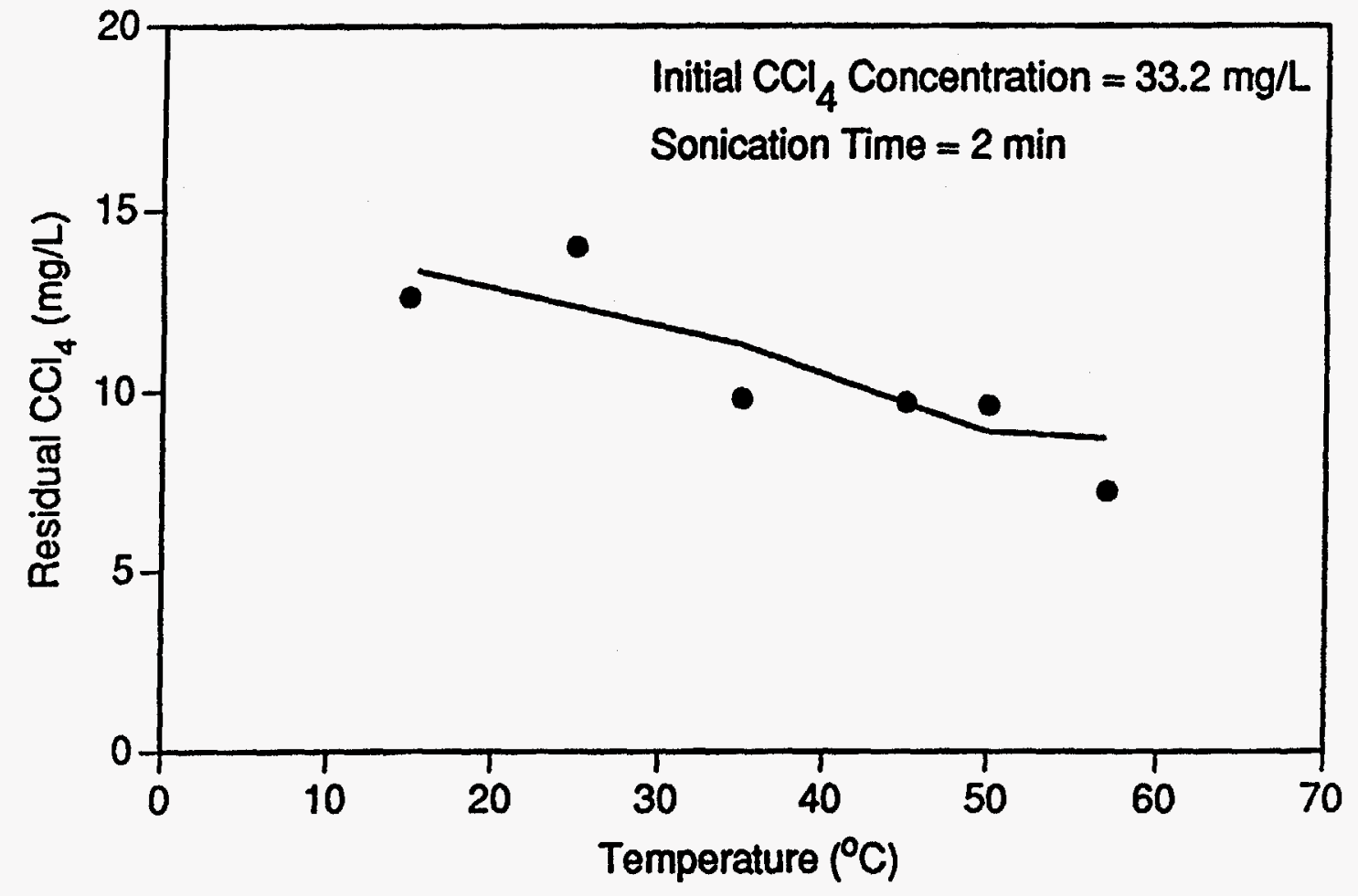

Figure 5. Residual $\mathrm{CCl}_{4}$ Concentration versus Steady-State Operating Temperature 


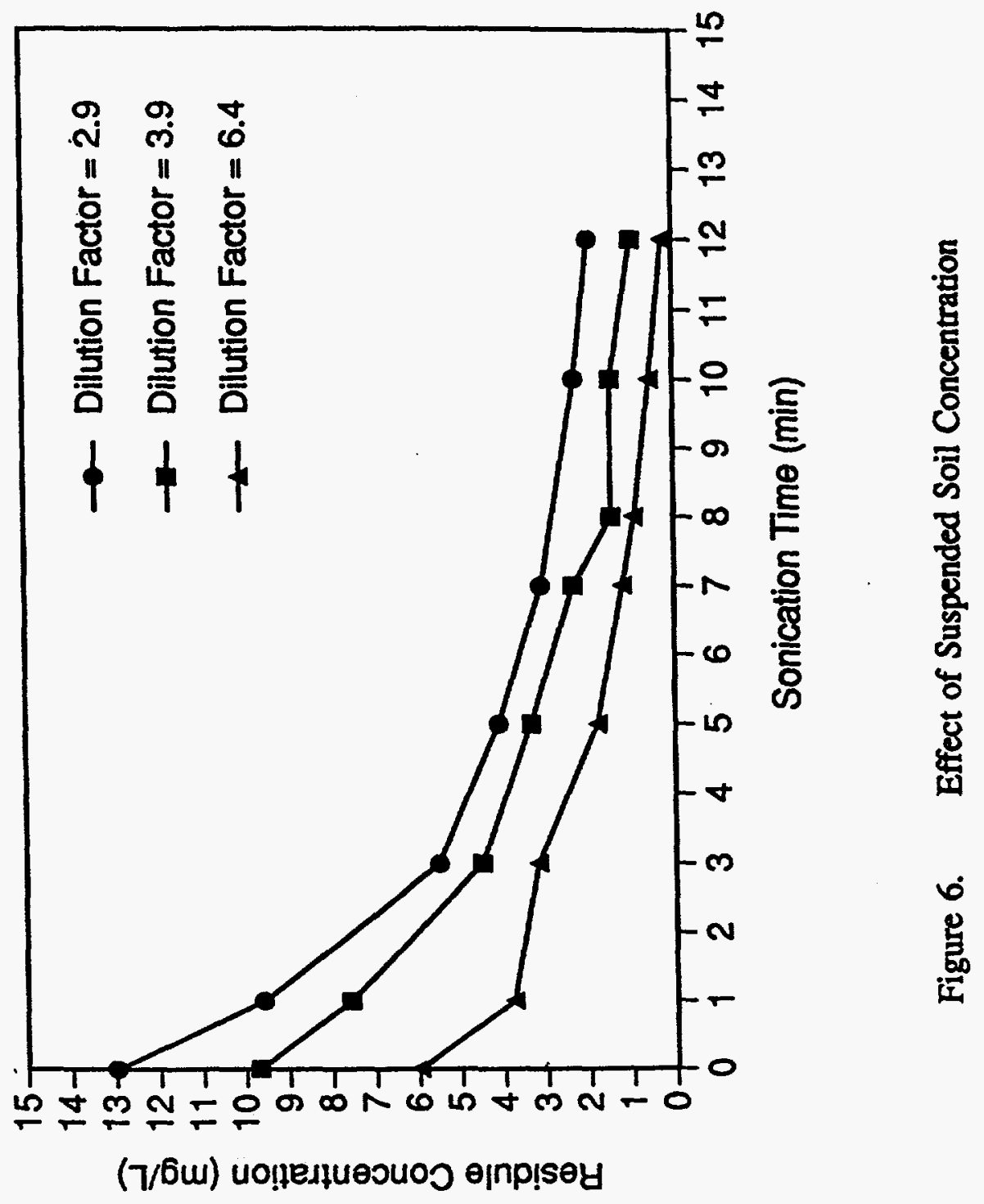




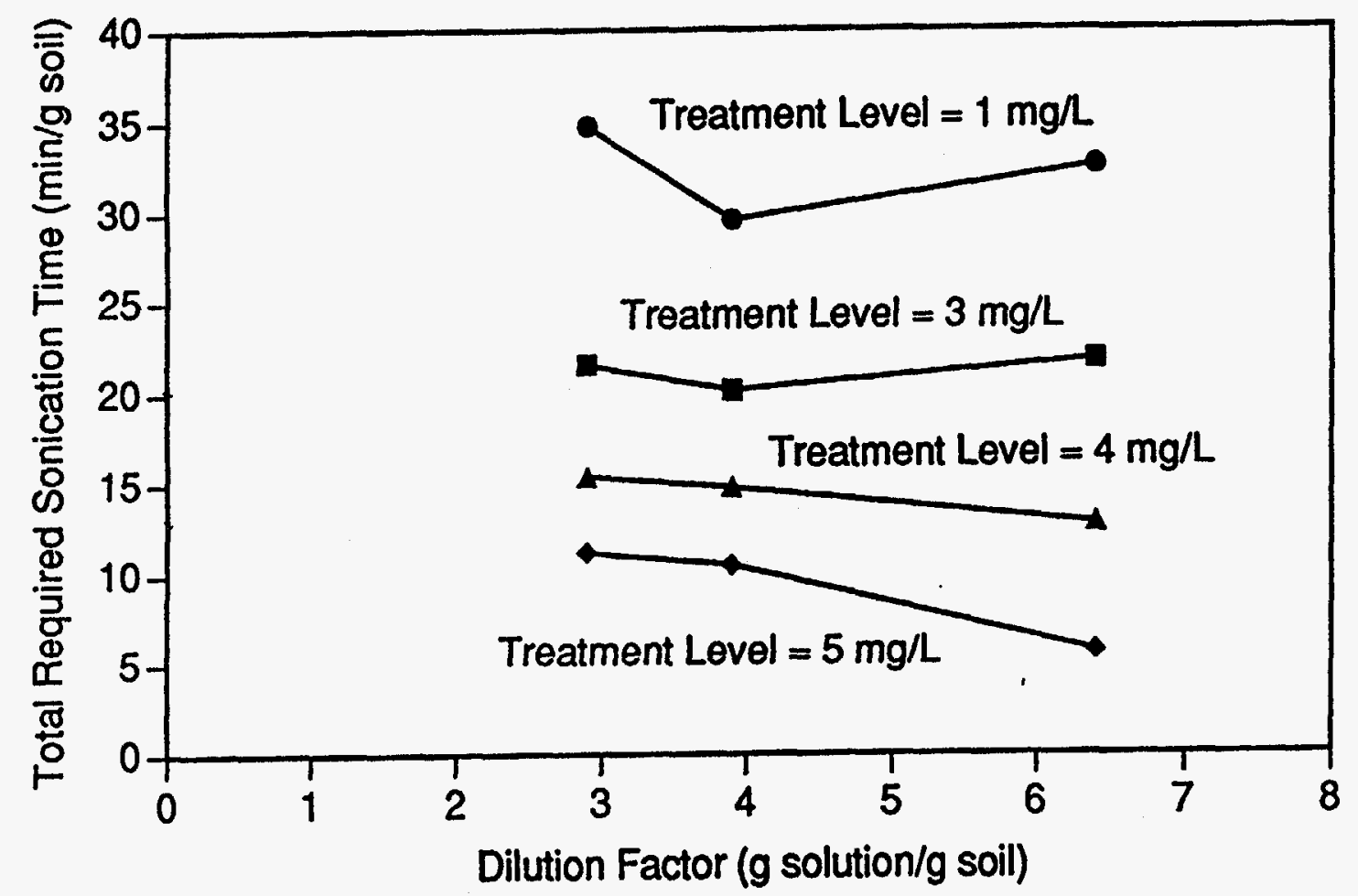

Figure 7. Total Required Sonication Time versus Dilution Factor 


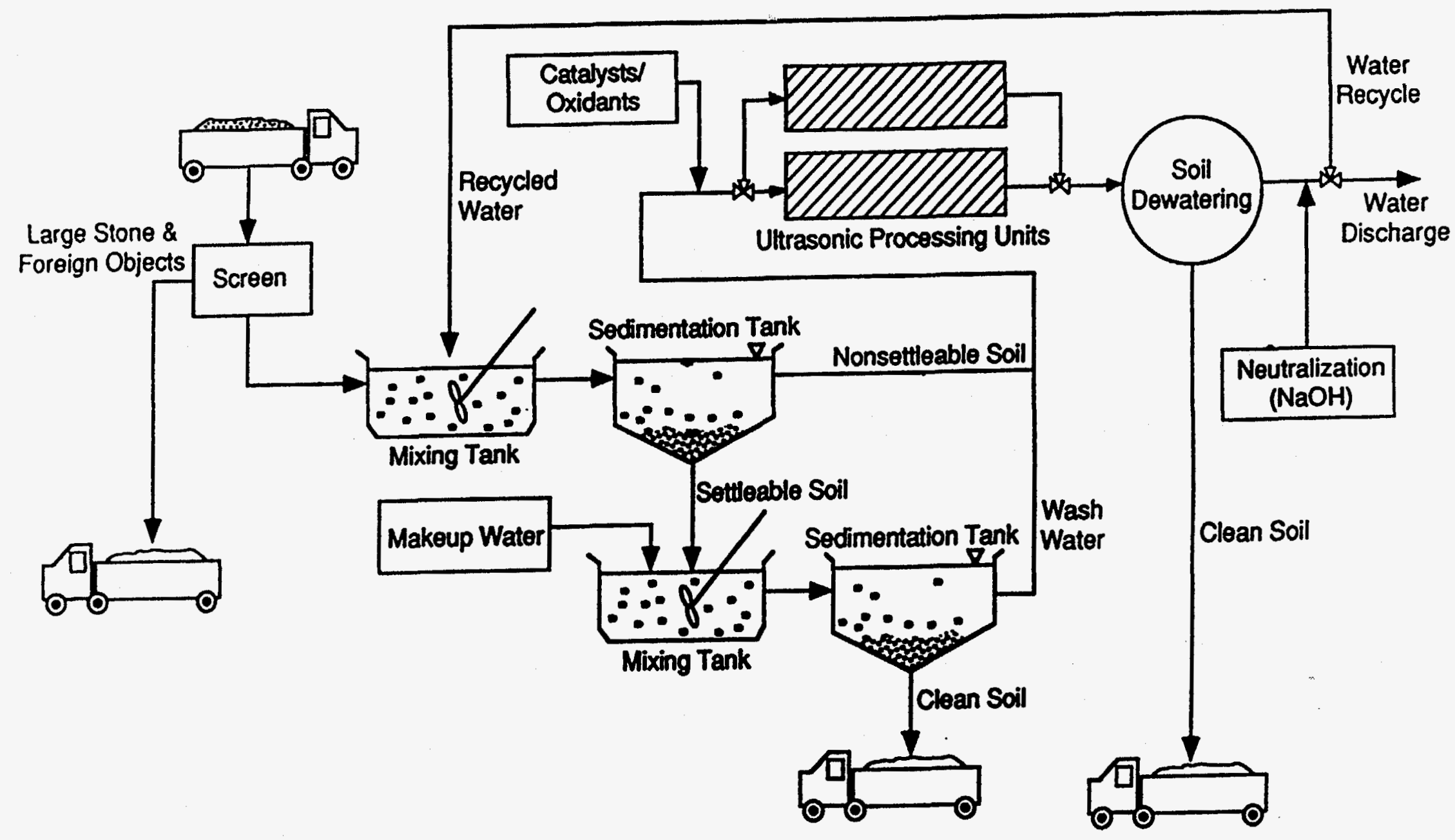

Figure 8. Ultrasonic Process for Detoxification of Contaminated Soil 